\title{
SooLics (Smart Room for Learns Physics) with Augmented Reality Sound Technology Based on Camera as a Physics Learning Room for Blind Students
}

\author{
Eko Pardiyanto, Zulfiqar Fatah 'Izzulhaq*, Riyan Tsabit Janany \\ Departemen Physics Education, Faculty of Science and Technology of UIN Sunan Kalijaga Yogyakarta \\ J1. Laksda Adisucipto, Papringan, Caturtunggal, Kec. Depok, Kabupaten Sleman 55281 Daerah Istimewa Yogyakarta, Indonesia. Telp. 081327604103 \\ Email*: fatahzulfiqar90@gmail.com
}

\begin{abstract}
A good educational process is one that is able to encompass existing communities, not expection for children with special needs. But the lack of adequate facilities makes them lack of maximum learning. SooLics (Smart Room for Learns Physics) with Augmented Reality Sound Technology based on Camera as a learning room for children with visual blindness is a room specifically designed for children with visual blindness to improve understanding about physics. In contrast to the usual learning room, Augmented Reality Sound Technology is used for visualization of physical matter that has been prepared in the room as a "visual aid" for children with visual blindness. We use Research and Development (R\&D) methode which is consists of defining studies (define), the design phase (design), and development. This research uses a camera which is specially designed to be used as a scan media for markers on augmented reality technology that has been prepared and installed in the room and the results are sound about physics matter. This room is designed so that blind children can learns independently.
\end{abstract}

Keywords: Augmented Reality, Blind, Education, Learns, Physics

\section{INTRODUCTION}

Being a general realization that mastery of science is a fundamental need to be achieved, proved to be none of the families who do not want to have their children to be educated. Many successful people are evidence of the importance of studying science. One of the branches of the knowledge closest to everyday life is physics. The science of physics contains the phenomena that occur in the universe that contain various concepts. Some of the concepts given are too abstract for students for the visually impaired children that require media as a tool of understanding. It is backed by a legal instrument which is written in the Constitution 1945 article 31 paragraph 1 where it states that every citizen has the same opportunity of obtaining an education. Further stipulated in the National Education System Act No. 20 of 2003 of the eleventh section of article 32 which states about the obligation of the Government to hold special education, which is education for students who have level of difficulty in following the learning process due to physical, emotional, mental, social, and or other potential intelligence and talent. Increased quality of human resources evenly including disabled people occupy a risky position to gain more attention. In accordance with this, the rights Convention of Children who ratified Indonesia since about 1990 states that education is the right of every child (Erwin, 2011).

The blind child has an advantage in the sense of hearing, when the five senses do not function then the rest of the senses become more sensitive and sensitive.
Learning activities in the classroom especially the physical lesson material for the blind child is too difficult. Some physics lesson materials regarding celestial bodies and atomic structures are too abstract because they are not found in everyday life. The role of the teacher becomes very important in delivering the material so that they can understand the concept, but each child must have a desire to dig its potential by selfstudy at home. The limitation of learning Media is again a separate obstacle for the blind child.

Hendra Suwardana in Sigit (2018) states that the last decade can already be called into the fourth phase (4.0). The fourth phase (4.0) has brought digitisation and automation to the manufacturing mix of Internet. The fruits of the 4.0 industry revolution are the emergence of disruptive innovation phenomenon ranging from industry, economics, education, politics, and so on. The advantage of this phenomenon is the technology that facilitates the most specific human activity for the education world. The need for education especially for the disabled is clearly assisted by the ease of access to education and the technology of its visitors. Based on the above background, this research will be created a special room for the blind child who can improve the understanding of physical material. Unlike the usual learning rooms, Augmented Reality technology is used as the visualization of physics materials that have been prepared in the room, so that blind children can learn independently. We offer Soolics (Smart Room to learning Physics) with the camera-based Augmented Reality Sound technology as a physics learning room for 
the blind child. This special room is expected to assist the blind child in understanding the physics material.

\section{Formula problems}

The problem formulation of this research is how is the design of Soolics (Smart Room to learning Physics) with Augmented Reality Sound technology based cameras as a physics learning room for the visually impaired child?

\section{Purposes}

The aim of the study was to develop Soolics (Smart Room to learning Physics) with the camera-based Augmented Reality Sound technology as a physics learning room for the blind child.

\section{Benefits}

The benefits of this research are:

Provide solutions to understand the concept of physics material through a special room for the blind child as a medium in the delivery of physical materials for blind children. Provide an alternative problem of physics for materials that are not found in everyday life. Facilitating the blind child to study independently. Develop psychomotor ability of the blind child

\section{MATERIALS AND METHODS}

The research methods used are research and development methods (Borg \& Gall, 1983) or researchbased development. These are the processes used to develop and validate certain products. The procedure in this study used 3-D models adapted from the development of a 4-D model device (four D model) as presented by Sivasailam Thiagarajan, Dorothy S. Semmel, and Melvyn I. Semmel (1974). This Model consists of 4 stages of development, namely Define, Design, Develop, and Disseminate. Based on the research plot, the research phase is divided into three main phases:

\section{Level Define (defining)}

This stage is conducted covering needs analysis, material analysis, determination of learning resources. Analysis needs aim to bring up and establish basic problems encountered in learning. Material analysis and determination of learning resources aims to summarize the results of the concept analysis to determine the fundamental ability of the research object. Researchers should understand the characteristics of participants because they will influence in this research. The characteristics considered in this study are: individual academic ability, group work ability, learning motivation, previous learning experience, individual practice skills, and so on. Physics is one of the mapels that demands the child to move because with the direct experience it can foster a more imagination for the child.

\section{Stage Design}

At this stage include the selection of formats, material literature study, preliminary design and products. The media format selection aims to identify the relevant learning media and determine the format in which to design the product to be developed.

\section{Literary studies}

The study of literature is an early stage enhancement of the field studies that have been gathered. The stage of literary studies is a stage in collecting supporting theories in research such as the theory of education, physics, visual impairment, Augmented Reality and the Industrial Revolution of 4.0. Literature studies can be obtained from journals, books, scientific works, articles, and previous research.

The product design stages are divided into three phases:

\section{a. Design Marker}

The marker design begins with creating frames and symbols for each of the sound divisions that appear. Here are examples of frames and symbols on marker making.

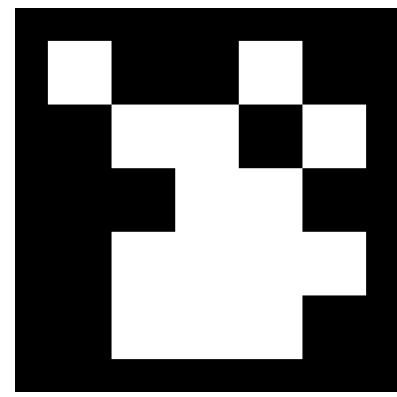

Figure 1. Frame and symbol on marker.

\section{b. Sound Designing}

Sound or sound is made by recording and editing to fit the required format, once the editing is forwarded again with matching sound and objects. The Software that is used for editing Adobe Audition CS 7 and sound recording using the Record tool.

\section{c. Tool Design}

In designing tools, It takes a computer camera that is integrated into the computer as an image capture tool or marker, which is placed on the user's head by modifying the tool. The tool consists of a computer camera given the addition of an LED light around it that serves as an additional illumination for the camera, and assembled in such a way that it can be used at the user's head.

In today's technological advances, the visual aids are evolving as the technology progresses rapidly. The earliest tool used by the visually impaired is the blind wand whose working principle is an extension of a blind person's hand to feel or touch the objects in carrying out their activities, until now the tool is still Be the best tool 
for visually impaired. The working principle of the blind stick that triggers developing tools is the same principle but assisted by the addition of electronic components such as sonar, sensors, and ultrasonics to enhance the function of the blind stick.

\section{Phase Develop (development)}

At this stage, includes validation and revision, small field trials and product revisions, large-scale field trials and final products. The initial product was validated first by some experts. Expert validation results are suggestions and feedback on tool improvements. After that, revision of the appliance. Later assessments with some experts are material experts, media experts, and evaluation experts.

\section{RESULTS AND DISCUSSIONS}

What is Soolics (smart Room to learns physics)?

Soolics (Smart Room to learns physics) with camerabased augmented reality sound technology as a physics learning space for visually impaired children is an innovation of learning in the world of education. This medium is precisely used for children who have cognitive abilities in a concrete stage of operation (when the child can think logically about a concrete event) to formal operations (teenagers think in a more abstract way and Logic) on voices and psychocomauthorics in the process. In the world of learning education with a room like this does not exist, visually impaired students only tend to be static in learning because of the limitations of existing facilities, so that the learning is only one-of-a-kind. But with this specially designed room the blind students can feel different pembaldoctrinal processes because they are required to move and feel themselves.

\section{Software Architecture Scope}

To design and create this visually impaired mobility aid it takes three types of supporting software (software). The first sound editing software in order to be in accordance with the format needed in the system, the next software for the marker making, and the last software is the Software builder augmented reality application itself. After studying and considering.

Here are the appropriate software to use:

\section{Adobe Audition CS}

Adobe Audition CS is the main program for sound editing in this study. Part of the process of sound editing stage and sound format converter are all done in this program.

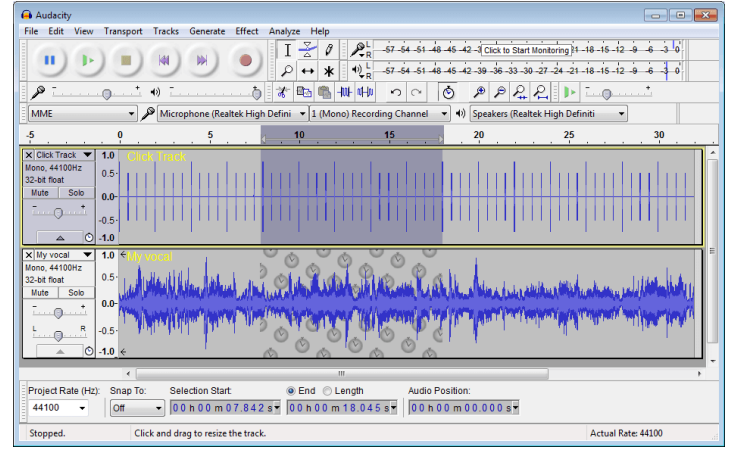

Figure 2. Adobe Audition CS Display.

\section{Corel Draw X7}

Corel Draw $\mathrm{X} 7$ is a bitmap-based image processing Software. Corel Draw X7 In this study used to create symbols on the marker.



Figure 3. Corel Draw X7 Display.

\section{ARToolKit Software Library}

ARToolKit is the main library that builds augmented reality apps. Created by Dr. Hirokazu Kato in the C++ language using Microsoft Visual Studio 2008. At first the main purpose of this library is to perform visual imaging to the real world in an overlay. As the development of ARToolKit also added a sound library where the sound is raised in real-time.

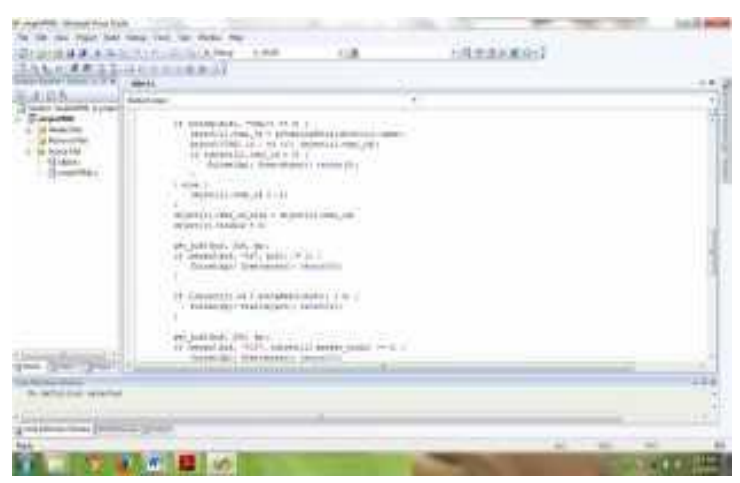

Figure 4. ARToolKit Display Software Library. 
ARToolKit uses a video tracker, to calculate the actual camera position and orientate the pattern on marker paper in real-time. The standard ARToolKit Software cannot read sound files, therefore coding on SimpleVRML must be added for voice file dialing. Open the SimpleVRML file on ARToolKit > Examples > simpleVRML > SimpleVRML by using Visual C++.

Here's the coding sound that is added to ARToolKit:

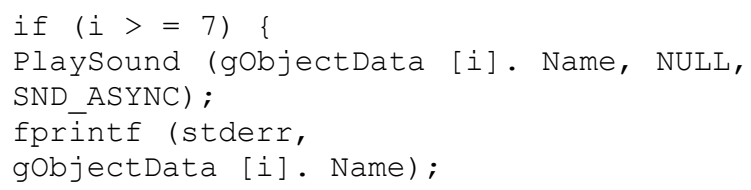

ZThe first line of coding serves to invoke the sound on the $>=7$ array. After adding coding, the SimpleVRML file is build and save as ARSoundZia. To select a storage location, select Project > SimpleVRML Properties. Then select Configuration Properties > Linker > General. Rename the Output File with ARSoundZia. exe.

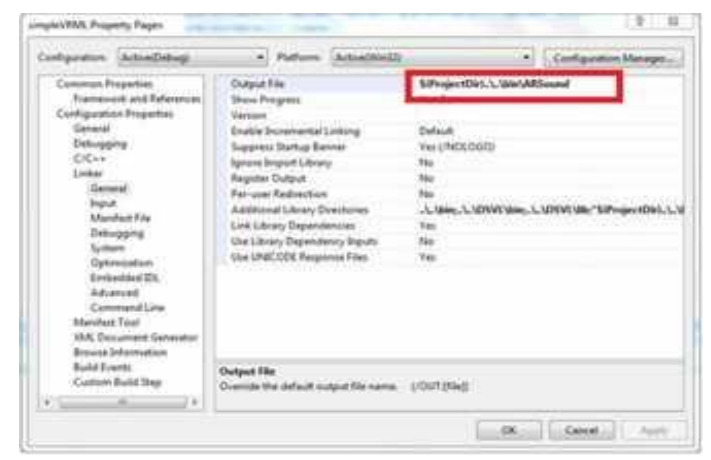

Figure 5. Setting location and File .exe.

\section{Application concept Work}

In this study used an application that is the detection of a marker program and translates into a sound that has been undergone a process using supporting software such as ARToolKit that works as an augmented reality software that helps translating marker-marker images into binery and matching in pre-inserted sound voices and displayed in real-time. In this study augmented reality sound was developed into a physics learning tool for visual impairment. Here is the process of how the visually impaired mobility aids in the image below:



Figure 6. Concept work Application.
Here's a flowchart from this prototype:



Figure 7. Prototype.

Explanation of flowchart above, namely:

1. Start

It is the initial flow to start something the program will run. Render the initial file. It is the process to read the files that will be prepared.

2. Looking for marker

Search marker process that you want to be introduced.

3. Identification marker

Is the desired marker detection when the marker is appropriate, if the marker detection is wrong then the process will not be resumed.

4. Position and direction of the object

Positioning and direction of the object with appropriate to bring up the desired sound.

5. Render Sound

It is the process of rendering the desired sound after performing the previous process.

6. Raising the Sound

Is the appearance of the desired sound.

7. Exit

It is the termination of the working process of the program.

8. Done, and quit the program that was done. 


\section{Hardware planning Scope}

In designing this smart learning room will use a camera tool that is placed on the blind head, the camera that is placed on the user's head is intended to facilitate in determining which direction the marker image is. Marker that is a symbol or image is placed in each direction of the road, barrier, room, objects, or tools that are located around the house. With the software (software) It is also necessary hardware (hardware) with the supporting specifications of the three software that has been described below.

Here are the required standard hardware specification tables:

Table 1. Recommended Hardware Specifications.

\begin{tabular}{cll}
\hline No & Hardware Component & Minimum Specification \\
\hline 1 & Processor & Pentium 4 (2Ghz) \\
2 & Random Access & $512 \mathrm{Mb}$ \\
& Memory (RAM) & \\
3 & VGA (Chart) & $128 \mathrm{Mb}$ \\
4 & Hardisk (HDD) & $250 \mathrm{Mb}$ \\
5 & Monitors & $1024 \times 768$ pixel \\
6 & Camera (Webcam) & 5 Mega pixel \\
7 & Printer & Standard \\
\hline
\end{tabular}

The specifications of the hardware components above are not a definite requirement in this study. In this study the consideration is the use of cameras (webcams) used. The larger the camera resolution the better the camera captures the image on the marker.

Below is a picture of the basic scheme of the visually impaired mobility aids design for Physics learning:

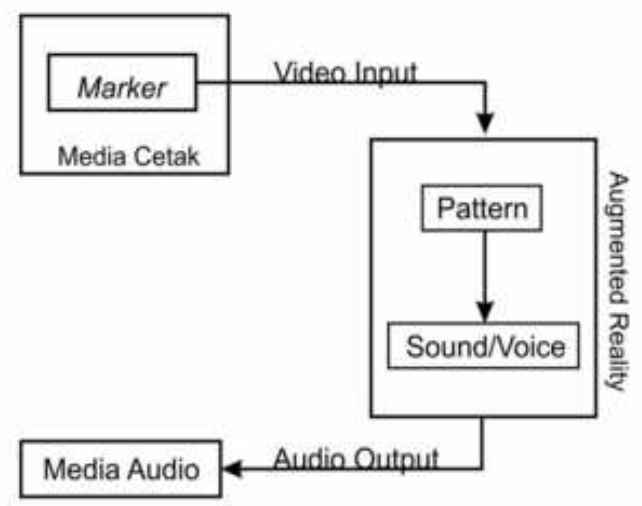

Figure 8. Basic research Scheme.

In the scheme image above seen the media structure is divided into 3 that is in the physical form of the printed media, an augmented reality application program connected and mutually integrated, and the media sound that serves as the production media sound/voice. The components that must be made are marker, pattren, and sound/voice.

The most important part in augmented reality is marker, and in the design of the marker cannot be done arbitrarily. Designing and making markers should follow the following standard augmented reality rules:

1. Marker must be black in order to facilitate the marker detection calculation process.

2. Marker used rectangular shape.

3. Thick marker shape is recommended at least $25 \%$ of the length of the outline marker.

The size of the marker printing will also affect the camera's response when the size is large then the marker can be detected within the required range, and when the size is small it needs a close distance to detect the marker.

The camera used in this study used a 5 MP (External) camera with a PC Camera brand, which has been adapted for the sake of this research. Camera used in the form of head flashlight that has been modified according to the needs of the research. This modification camera is equipped with a battery, LED light, rubber binder for the head and camera located right in the middle, the camera added on the head flashlight is connected with a USB cable to connect between the camera and laptop.

The LED light that is on the modification camera works when the lighting condition is not as bright as the room, the LED light can be used as additional lighting that is manually activated. The Led is sourced in a rechargeable battery.

Here is the electronic circuit for camera modification with LED lights:

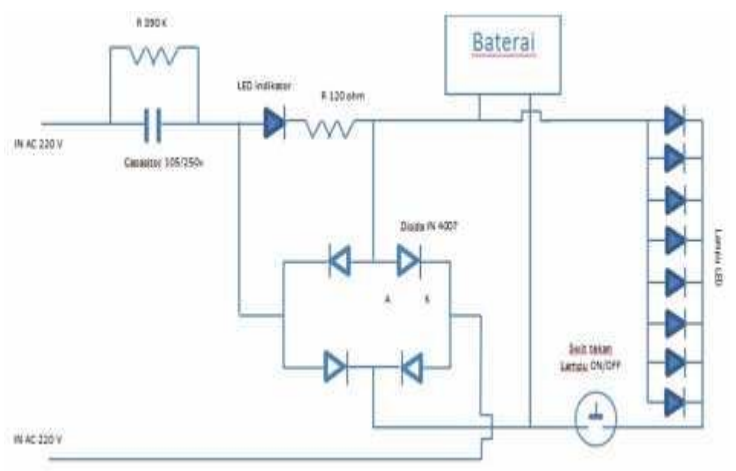

Figure 9. Rangkain Led light on camera modification.

The following components are used on the LED lighting circuit:

- 2 pieces Resistors

- 1-piece Capacitor 105/250 V

- 4 Diodes IN 4007

- Battery CAs

- 1 piece LED Indicator

- 8 Pieces LED Lamp

Here is an illustration of the use of tools in the process of learning physics in a room with solar system material and atomic theory: 


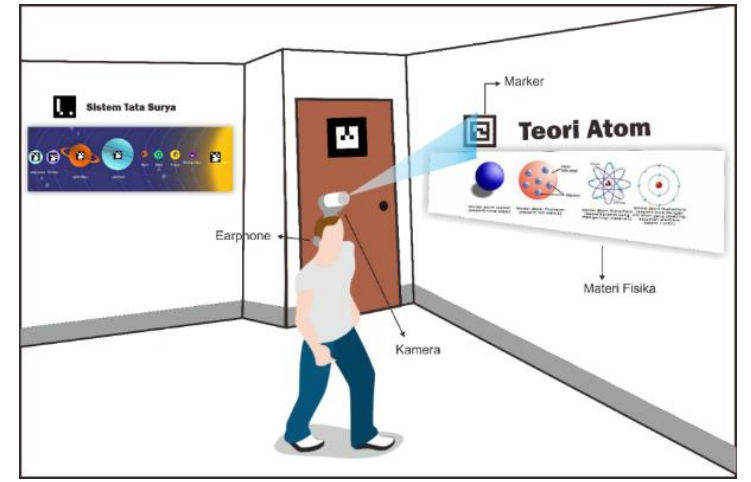

Figure 10. Illustration of the use of Soosics.

How to work Soolics (Smart Room to learns physics) Soosics on its base use Augmented reality sound technology that changes the marker mounted on an object which is then transformed into a sound form describing the material presented. Not only in the form of sound but also equipped with physics tools that are specific to the visually impaired.

There are two basic things that work on Soosics (Smart Room to learns physics) that are hearing and tactile.

\section{Hearing}

The creation and editing of Sound that has been conceptualized in the form of instruction of State or even location and also physical materials, referring to the reference that has been collected previously. Voice recording is performed using a recording tool that is high record quality with WAV sound format. After the sound recording stage has been completed, it continues with sound editing stage to sound using Adobe Audition CS software. The purpose of editing is to refine, cut, and change the sound format to make the sound result According to the needs of augmented reality sound application. Marker that is transformed into sound form will be channeled through headseat which is placed in the ears of the visually impaired students. Automatically when the camera is already working by detecting the marker that has been installed, the physical material will be heard.

Here are examples of sentences to be recorded and used:

Table 2. List of sentences.

\begin{tabular}{ll}
\hline No & Sentence \\
\hline 1 & "Before you are a door" \\
2 & "The solar system consists of several planets...." \\
3 & "The atomic Model there are several kinds of...." \\
4 & And others \\
\hline
\end{tabular}

The above sentences will be tailored to your existing learning needs. With instruments that are visually impaired students can use their hearing skills to learn the physics of existing materials. For example, on the solar system material and atomic model.

\section{Finger/touch sense}

Not only in the form of sound, as a smart room learns physics, this room also features some special physics props for the visually impaired in it. With the marker that has been installed in the room The blind students will be instructed about what to do. These special props are equipped with Braille letters, so that the blind students can do so.

In general, this Soosics (Smart Room to learns physics) is like a "museum" for visually impaired students, where from the start of the walk in front of the entrance is set and given specific instructions on what to do and what is in it. Inside the room itself is set about the physics material that will be studied, where there are two types of material to be delivered that is in the form of sound or sound output and with the meaning. By using augmented reality sound technology that converts the command marker into sound form, it will automatically sound the command sound or physical material through a headset that is placed on the ear of the visually impaired students. This process begins with a modification camera mounted on the blind student's head, like picture 14. This camera is used for the scan marker process that has been installed in the room.

This room is specially designed so that the blind students can learn independently about the physics material, especially with the direct practice of feeling what is in the room, so in addition to practicing cognitive skills also train psychomotor skills Visually impaired students. For the completeness of others this room is equipped with a teaching material in the form of Braille modules about the material learned in the room.

\section{Soolics (Smart Room to learns physics) implementation}

The difficulty in learning for visually impaired students is how to foster imagination about the material being delivered. Learning by just being delivered in class with auditory processing alone will not be effective in delivering the material. Physical subjects are one of the subjects that are difficult to teach to students who are visually impaired, so it is necessary to do something different in the process of learning.

Through Soolics (Smart Room to learns physics) with the camera-based augmented reality sound technology as a physics learning room for children visually impaired, the child will be invited to enter into a different and interactive learning process. Augmented reality sound technology and Braille help make the process of visualization of physics material better and more tangible. Demanding children to move in the room will train the child's independence and their psychomotor skills as well as cognitive abilities in the study of existing physical materials. 


\section{CONCLUSION}

From the discussion that has been submitted, it can be concluded that Soolics (Smart room to learns physics) with camera-based augmented reality technology as a physics learning room for child Blind is a media design Interactive, auditory and tactile-based physics learning that is used to facilitate the visually impaired students in understanding the existing physics material. There are two basic things that work during this learning process that is the sense of hearing and tactile. It works with the scan marker process using a modified camera that is mounted on the head and then transformed into the sound form. With augmented reality sound technology used will sound either instruction or material on a headset that has been placed on the ears of a visually impaired student. The implementation of this Soolics (Smart Room to learns physics) is that it allows students to learn physics independently with different and interactive processes involving the cognitive and psychomotor skills of the blind child. With safe goods and a friendly design Soolics (Smart Room to learns physics) deserves to be used as one of the media in conveying physics material.

\section{Suggestions}

In terms of camera devices used can be developed more efficiently and effectively with a simpler design but with a high pixel size, so the result will be better and maximal. The design of Soolics (Smart Room to learns physics) made more neat, well setup marker and items that are in it. Design the audio system should be well considered, so the result will be maximal.

\section{REFERENCESS}

Azuma, Ronald T. 1997. A Survey of Augmented Reality. Presence: Teleoperators and Virtual Environments.

Arsyad, Azhar. 2015. Media Pembelajaran. Jakarta: PT Raja Grafindo

Diah, W. 2012. “Ketunanetraan, PDF”. Dalam http:// eprins. uny. ac.id, 21 Januari 2018, 13.58

Freedman, Young. 2002. Fisika Universitas Jilid 1. Jakarta: Erlangga

Masruro, Erwin Arsadani. 2012. Pengembangan Termometer dengan Output Suara Berbasis Mikrokontroler Atmega 8535 dan Bahan Ajar Pembelajaran Fisika di SMPLB A [skripsi]. Yogyakarta: UIN Sunan Kalijaga.

Priatmoko, Sigit. 2018. Memperkuat Eksistensi Pendidikan Islam Di Era 4.0. Jurnal Studi Pendidikan Islam, Volume 1 No. 2

Rifana Arief dan Neli Umniati. (2012). Pengembangan Vitual Class untuk Pembelajaran Augmented Reality Berbasis Android. JPTK UNY (Vol. 21, No 2). Hlm 114-122

Sugiyono. (2016). Metode Penelitian Kuantitatif, Kualiitatif dan $R \& D$. Bandung: Alfabeta 
THIS PAGE INTENTIONALLY LEFT BLANK 